\title{
The Effect of Job Burnout on Employees' Satisfaction: A Comparison Study between Public Universities and Private Universities in Jordan
}

\author{
Naser Khdour \\ Business Administration Department, Philadelphia University, Jordan \\ E-mail: nkhdour@philadelphia.edu.jo \\ Omar Durrah \\ Hospital Management Department, Philadelphia University, Jordan \\ E-mail: odurrah@philadelphia.edu.jo \\ Martin Harris \\ School of Business, Essex University, England \\ E-mail:martinh@essex.ac.uk
}

$\begin{array}{lrr}\text { Received: May 10, } 2015 & \text { Accepted: June 14, } 2015 & \text { Published: July 1, } 2015 \\ \text { doi:10.5296/jmr.v7i4.7790 } & \text { URL: http://dx.doi.org/10.5296/jmr.v7i4.7790 }\end{array}$

\begin{abstract}
This study seeks to shed light on the phenomenon of job burnout, and its prevalence amongst the staff and seeks to address the issue of the level of job satisfaction in Jordanian universities, together with the examination of the effect of job burnout on job satisfaction. The study adopted a descriptive analytical approach through a comparative study between public universities and private universities, and used the questionnaire as basic tool for data collection, which was distributed to a sample of (200) members of the administrative staff in Jordanian public and private universities. The study found that the degree of job burnout experienced by the administrative staff in the university sector was more than average, Showed that low personal performance dimension has ranked the first as the most persistent job burnout dimension then physical and emotional exhaustion then negative attitude towards relationships. It observed that the degree of job burnout in public universities was greater
\end{abstract}




\section{Macrothink}

Journal of Management Research

ISSN 1941-899X

2015, Vol. 7, No. 4

than in the private universities. The level of staff job satisfaction in the public universities was less than that observed in private universities. The study showed that no dimension of job morally affects on employees satisfaction in public universities. while only one dimension (low personal achievement) affects employees satisfaction in private universities.

Keywords: Job Burnout, Satisfaction, Emotional and Physical Exhaustion, Passivity, Personal Achievement, Jordanian Universities 


\section{Introduction}

Job burnout has been the concern of many researchers in the field of administrative studies due to the importance of this subject and its direct relationship to a significant set of organisational changes that affect the success, development and advancement of organisations and their ability to achieve their goals in the required effective and efficient way. These organisations persistently seek to take care of employees in various fields of work, as they believe in their importance in building and developing their societies in general and their organisations in particular. They provide their employees with different caring methods. However, it does not mean that their fields of work are free of obstacles which prevent them from finding complete satisfaction in their roles. There are several stressful situations that challenge employees at work, causing employees to feel stressed and worried in a way that may adversely affect their personal lives in general and their work in particular. Hence, the severity of continued pressures cause negative impacts; mostly a job burnout. On the other hand, employee satisfaction represents a main motivation for individuals to increase their efforts to achieve a higher level of performance. This aspect also constitutes a significant factor as an indicator of success for the person in the various aspect of their life.

\section{Research Problem}

In light of the recent challenges and developments in Jordan's educational sector, competition between public universities and private universities have increased, and so universities have been obliged to improve and develop their services to maintain continuality and to survive. As a result of which, employees in these universities have been subjected to greater tensions and pressures in order to satisfy such demands. Therefore, the accumulation and continuality of such increased burdens in a tense environment abolishes any attempt to renovate and innovate and leads to burn out, causing psychological problems, performance setback and dissatisfaction.

\section{Research Questions}

What are the levels of job burnout among employees at the universities?

Does the level of job burnout among employees in public universities differ from the level of job burnout amongst employees in private universities?

What is the level of employees satisfaction at public universities and private universities?

Does the effect of job burnout's dimensions (emotional and physical exhaustion, negative attitude towards relationships and low personal achievement) on employee satisfaction in public universities differ from its effect in private universities?

\section{Research Importance}

The importance of this research is located in:

The importance of job burnout due to its dangerous negative impact economically and administratively. 
The important role of human resources in performing their tasks effectively inside universities in a way that improves the quality of the educational service provided.

Universities constitute important and vital organisations in the provision of educational services for students. Additionally, they provide researchers with opportunities for training, implementation and utilisation.

Deficiency of applied studies and research on the concept of job burnout; particularly in the educational sector.

\section{Research Objectives}

Highlight the phenomenon of job burnout and identify its scope amongst the employees of Jordanian universities.

Identify the levels of job satisfaction among employees of the Jordanian universities.

Study the effects of each of the job burnout dimensions on employee satisfaction in public and private universities.

Provide a set of recommendations and suggestions for administration leaderships in private and public universities to treat job burnout amongst employees, mitigate its impact and improve job satisfaction levels.

\section{Literature Review}

Cited (Maslach, 1982; Linthicum, 1994) definition of the term 'burnout' has been accepted in that his model defines three separate elements, which are considered to co-exist - that of de-personalisation, a decreased level of personal accomplishment and emotional exhaustion. Burn-out's initial stage is normally exemplified by an excessive level of general fatigue caused by daily human contact, together with a considerably increased level of exhaustion emotionally. This consequently causes an increasing level of antagonism and negativity towards other individuals, particularly towards clients, and this leads to a decrease in the individual's personal accomplishment, and all these states are a consequence of work pressures.

\subsection{Personal Accomplishment}

Interestingly, (Maslach \& Jackson, 1996) argue that it is possible to conceive of the state of burnout as a continuous, constant variable, which varies from high to low degrees in the individual's feelings. (Maslach \& Jackson, 1993) earlier observed that emotional exhaustion was the initial serious indication of burnout and it results from when the emotional resources are insufficient to meet the demands of the job. They argued that this initial indications of burnout syndrome was a result from the depletion of the emotional resources and from individuals considering that they were not able to work and contribute any more at an emotional, psychological level.

The daily pressure of work, or the possible emotional overload can cause feelings of extreme fatigue and overextension (Whitaker, 1996). The enormous amount of psychological energy 
demanded by the actions of caring and empathy, (Chemiss, 1980) along with coping and stress occasionally are critically depleted and therefore has given rise to the useful term 'emotional exhaustion' in the diagnosis of professional burnout.This subscale - emotional exhaustion - was observed by (Cordes \& Dougherty, 1993) to be evident, regardless of the individual's occupational setting, but it had been noted that if an individual was not in receipt of emotional support in the workplace, then the occurrence of emotional exhaustion appears to be significantly high in its occurrence. Burnout was observed to be strongly associated with the lack of positive, professional.

\subsection{Depersonalisation}

The coping device of depersonalisation is, as (Maslach, 1982) argued, results in circumstances where high levels of emotional exhaustion are experienced. Cynical attitudes and negative feelings an individual holds about their clients whilst experiencing depersonalisation, can extend to dehumanised perceptions and callous views of other people, such as those which result in the individual considering that people deserve their trials and troubles and is marked through a growing impersonal response to the individuals who are in receipt of their services (Maslach \& Jackson, 1993). Emotional exhaustion and depersonalisation were observed by (Friedman, 1993) to be the most significant constructs in the assessment of the degree to which people experience burnout, together with chronic emotional exhaustion which has been observed to produce depersonalisation characteristics (Farber, 1991). (Cherniss, 1980) argued that by detaching oneself psychologically, it is possible to cope better and to conserve one's energy, plus the key construct in the assessment of burnout was the characteristics of depersonalisation.

\subsection{Decreased Personal Accomplishment}

Feelings of both self-esteem and competence are described by the term 'personal accomplishment' which is concerned with an individual's interactions with work colleagues (Maslach, 1982). To endeavour to discover the meaning of one's life, is mankind's essential motivational force, but job satisfaction becomes significantly reduced if individuals attempt to find excessive meaning in their work (Koeske, \& Thomas, 1995) and that over-involvement due to the need to develop a record of personal accomplishment in one's work, can lead to burnout. It is a clear sign that all is not well when one discovers that work accomplishments are diminishing and this can be the case if the individual has set their ambitions too high, such as people who aim to influence the world positively and for the better, such as in education. As (Hancock, 1995) observed, when the work itself appears to create very little difference, the idealists, who were originally attracted to the job, can become disenchanted and disheartened with their progress. This decrease in personal accomplishment, when experienced alongside depersonalisation and emotional exhaustion, form the key variables the assessment and identification of burnout (Maslach, 1982).

\subsection{Symptoms of Burnout}

(Maslach \& Jackson, 1996) have argued that "Burnout is a problem of bad situation rather than bad people" and whilst burnout has been conventionally considered to be an individual's 
problem, research over the last two decades has indicated that burnout is actually due to their working social environment. This was supported by (Maslach \& Leiter 1997).

\subsection{The process of burnout}

The state of burnout is not one which occurs overnight, but is a condition which results from a sustained period and is a slow process which can take many years. Burnout usually starts and develops in the initial stages of emotional exhaustion (EE). This can develop into higher levels and can be observed by an individual's withdrawal from colleagues, patients, clients, peers and other professionals, which results in a period of depersonalisation (DP). At this stage, the individual may develop a significantly cynical attitude in their approach to their peers, their colleagues, other professionals, their clients and their job (Tanis, et. al., 2005). Although (Maslach, et. al., 2001) suggested that EE could lead to DP in burnout, (Demerouti, et. al., 2007) argued that "the development of burnout follows two processes", and continued to suggest that the EE and the DP tended to develop in parallel, with different antecedents. They considered that the first process was connected to the demands of the job and often lead to overtaxing and consequently to EE.

The second process which results in an individual's disengagement from their work is initiated by an absence of social support together with inadequate job resources, for if the demands of the job are not met by the necessary resources, withdrawal behaviour will start to occur, and subsequently will lead to a state of disengagement (Demerouti, et. al., 2007). (PA) forms the third and final component of burnout, but is not viewed as a core feature of burnout, but is incidental to the burnout process. These three stages, as proposed by (Maslach, et. al., 2001) appear to currently form the most commonly accepted explanation of the development of burnout and its various stages.

\subsection{Burnout and related concepts}

\subsubsection{Burnout and stress}

The two states, stress and burnout, are frequently seen as similar domains. However, they differ significantly in the fact that the latter is the result of unabated, prolonged experiences of stress, as opposed to a particular acute stress episode (Maslach, et. al., 2001), which is a temporary adaptation process. Burnout, however, is a process of gradual sustained psychological erosion, one which is the result of various social and emotional chronic exposure (Leiter \& Maslach, 2001), which together with the inclusion of PA and DP creates a broader field of effect, as opposed to the established concepts of the effects of occupational stress. Although stress can be viewed as a predictor of EE (Kaden, 1999; Wertz, 2000) it does not solely and invariably lead to the condition of burnout.

\subsubsection{Burnout and depression}

Although the high rates of burnout linked with depression have resulted in a considerable amount of debate, depression is known as a clinical syndrome, one which pervades an individual's life in every domain (Maslach \& Leiter 1997) whilst burnout is a term which describes the situational crisis in an individual's work relationship, and with especial focus on 
their relationships with clients (Leiter \& Maslach, 2001).

\subsection{Individual aspects of burnout}

\subsubsection{Burnout and gender}

There does not appear to be a significant relationship existing between burnout and gender, Indeed, there exist some studies which have observed no differences in gender across the whole of the three dimensions of burnout (Rafferty, et. al., 2001; Dormann \& Zapf, 2004; Ben-Zur, et. al., 2005). However, there also exist some studies suggesting that men and women are individually susceptible to various different burnout dimensions, for example, men have been observed to be more susceptible to DP (Lewig \& Dollard, 2003), whilst women might be more susceptible to EE. (Dollard, et. al., 2000) observed that gender appeared to be unrelated to PA and EE, whilst males were associated with DP, and (Giebels, et. al., 2005) observed no differences in gender in EE. In cases where there was observed to exist gender differences, it has been suggested that perhaps this reflects a confounding of occupation and gender, and it could be possible that burnout is suffered more frequently by females working in predominantly female occupations, for example nursing, than in predominantly male jobs, for example policing, where they are more likely to exhibit signs of DP (Maslach, et. al., 2001).

\subsubsection{Burnout and length of employment (tenure)}

Job tenure was observed by (Zohar, 1997) to be associated in a significantly positive manner in connection with the burnout dimensions, and (Lewig \& Dollard, 2003; Deery, et. al., 2002) observed that there was a positive association with EE and job tenure. Although observing no association, either positive or negative between DP, or EE and job tenure, (Alexander, et. al., 2001) observed that ambulance workers' sense of accomplishment appear to be inversely proportional to their length of service.

Job tenure was observed to be significantly related in a negative manner to EE, by (Holman, et. al., 2002) whilst (Dollard, et. al., 2000) observed that in one of the studies EE appeared to be lower in experienced teachers, but the other study displayed no association. Nurses and home care workers were observed in a study by (Omdahl \& O'Donnell, 1999) and in another study by (Fajiwara, et. al., 2003) not be effected by the length of professional experience as regards to the three different burnout dimensions, and furthermore, (Giebels, et. al., 2005) observed there to be no association existing between EE and tenure in a sample group of social workers. Therefore, it appears that it would be extremely problematic to achieve any definite, firm conclusion concerning the relationship between burnout and job tenure.

\subsubsection{Burnout and occupation}

(Brotheridge \& Grandey, 2002) compared levels of burnout in various kinds of occupation, Significant differences in occupations and EE levels were not observed by this study. A few of the findings, however, have agreed with expectations and predictions regarding types of occupation which could possibly lead to burnout. It was concluded by (Schaufeli \& Enzmann, 1998) that after reviewing studies concerning a range of professions, teachers 
tended to experience and be susceptible to high EE levels.

\subsection{Relationship between job burnout and satisfaction}

(Tamini \& Kord, 2011) conducted a research to investigate the relationship between job burnout, life and job satisfaction. The sample applied on university of Sistan and Baluchestan. The results showed positive relationship between job and life satisfaction and negative relationship among depersonalization and emotional exhaustion. On the other hand a positive relationship between Personal accomplishment and both life and job satisfaction.

Another research by (Capri, et. al., 2012) studied the relations between burnout and satisfaction of university students. The sample consists of 354 students. The study found significant relations between burnout and satisfaction.

(Ozyurek, et. al., 2012) examined the relationship between job burnout on one hand and life satisfaction levels on the other. The sample was teachers and administrators in Karabuk in turkey. The life satisfaction levels of female teachers have been found higher than males' whereas the burnout levels of the teachers were higher than administrators'.

An investigated study by (Sangganjanavanich \& Balkin, 2013) examined the correlation along with burnout and job satisfaction. The study applied on therapist educators. The result came out to shed light on the importance of the link between job satisfaction and job burnout. The job satisfaction had a lower scored between counselor educators and higher levels with the three burnout dimensions, more precisely emotional exhaustion.

(Khamisa, et. al., 2015) conducted a research to investigate the relationship between different variables such as work stress, job satisfaction, job burnout and general health of nurses. 1200 nurses were the sample from four hospitals in South Africa. The research showed a negative effect of burnout on job satisfaction and that amongst nurses and other health professionals, resource inadequacy, staff management and security risks were mainly so important in determining burnout and job satisfaction.

Many of the studies such as (Hunsaker, et. al., 2015; Leung, et. al., 2015; Jasperse \& Dungey, 2014; Scanlan \& Still, 2013) emphasized importance of the relationship between job burnout and employees satisfaction of various organizations.

\section{Research Hypotheses}

$\mathbf{H}_{\mathbf{1}}$ : There are no significant differences of moral indications between public universities and private universities in terms of the level of job burnout.

$\mathbf{H}_{2}$ : There are no significant differences of moral indications between public universities and private universities in terms of the level of employees satisfaction.

$\mathbf{H}_{3}$ : Job burnout levels among employees in private universities and in public universities do not differ based on their demographic properties (gender, social status, age, experience and qualifications). 
$\mathbf{H}_{4}$ : There is no significant difference between the level of employee satisfaction in public universities and private universities and the level of natural employees satisfaction.

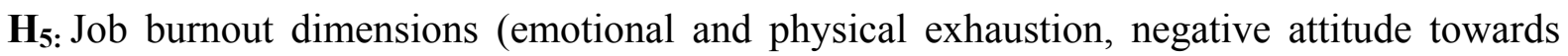
relationships and low personal achievement) do not morally affect on employees satisfaction in public universities and private universities.

\section{Research Model}

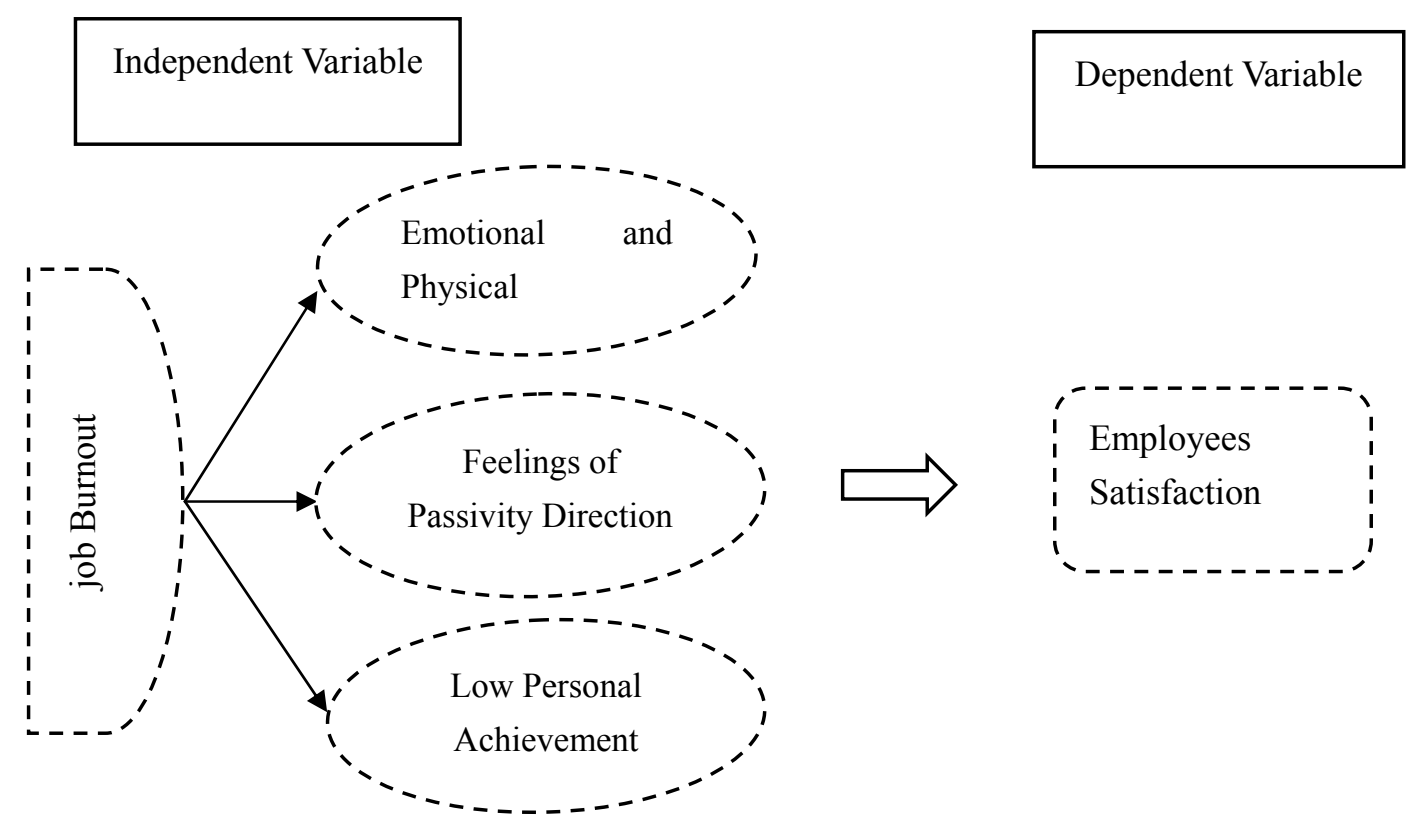

\section{Research Community and Sample}

The research community consisted of administrators staff at public and private Jordanian universities in all specialties. The study was implemented in 6 universities; three of which were public universities: (Balqa Applied University, University of Jordan and Yarmouk University) and three were private universities: (Philadelphia University, Irbid University and Jadara University). A random sample of 200 employees - 100 employees from public universities and 100 employees from private universities, was selected, as follows: 
1. Distributing items of the research sample

\begin{tabular}{lccc}
\hline University & Sector & No of Workers & Percentage \\
\hline Balqa & Public & 47 & 23.5 \\
Jordanian & Public & 30 & 15.0 \\
Yarmouk & Public & 23 & 11.5 \\
Philadelphia & Private & 43 & 21.5 \\
Irbid & Private & 24 & 12.5 \\
Jadara & Private & 32 & 16.0 \\
\hline \multicolumn{1}{c}{ Total } & - & 200 & 100.0 \\
\hline
\end{tabular}

\section{Research Tool}

The research tool has been crystallized by preparing a questionnaire after reviewing the theoretical aspect and previous studies. The five-Likert scale has been used for the research. The questionnaire consists of the following parts:

Part 1: includes demographic variables which are measured by 5 questions.

Part 2: to measure job burnout dimensions, a scale of 20 statements has been used. It includes 7 statements to measure emotional and physical exhaustion, 5 statements to measure the dimension of negative attitude towards relationships, and 8 statements to measure low personal achievement.

Part 3: to measure job satisfaction, a scale of 14 statements was used.

\section{Research Methodology}

This research depends on analytical descriptive methodology to reach certain goals and contains both an office study and a field study:

Office Study: aims to selecting a scientific material related to the research subject by reading books, letters, periodicals, Journals, articles, conference printouts, reports, researches and internet articles.

Field Study: aims to verifying the accuracy level of research hypotheses by studying the opinion of employees at the universities, subject of the research. It requires collecting, studying and analysing information by preparing a questionnaire.

\section{Statistical Analysis Methods}

The data was analysed and tested the validity of the hypotheses based on a set of statistical methods using program SPSS, V.22 and these methods were:

Cronbach's alpha coefficient.

Distribution of sample (frequencies and percentages).

Descriptive statistics (mean and standard deviation).

Independent samples t-test. 


\section{Mll Macrothink}

One samples t-test.

Levene test.

One Way ANOVA.

Kruskal-Wallis.

Mann-Whitny.

Multiple regression analysis.

\section{Research Borders}

Research has been limited to apply to administrative staff in 6 universities (Balqa, Jordanian, Yarmouk, Philadelphia, Irbid, Jadara) and the results of this research were intended only for those workers in those universities.

The research used three dimensions of job burnout (emotional and physical exhaustion, feelings of passivity direction relations, low personal accomplishment).

The research used satisfaction as one variable and was not studied through dimensions.

The confidence level of $95 \%$ has been used in testing the validity of the hypotheses and generalising the results.

Middle degree was considered as 3.00 and high degree was taken to be 4.00 on the Five Point Likert Scale.

\section{Results}

Validity: The validity of the content of the search tool was considered in terms of wording, clarity and comprehensiveness by arbitration where the tool formulation was based on the views of more than one previous researcher and presented to a group of experienced arbitrators and specialists and their opinions and suggestions in the light of observations, were considered and the tool was adopted in its final form.

Reliability: The reliability of the questionnaire has been verified by using an internal consistency coefficient (Alpha Cronbach's) and for the standard to have a stable scale the minimum value of the parameter in this test that it should not be less than 0.70 . The results in table (2) show that the value of Cronbach's Alpha coefficient for all research variables exceeds 0.70 accordingly it can state that all measures in the research have internal reliability for their terms. 
Table 2. Alfa Cronbach's coefficient for the study variables

\begin{tabular}{lcc}
\hline \multicolumn{1}{c}{ Variables } & Cronbach's Alpha & No. of phrases \\
\hline Emotional and Physical Exhaustion & 0.916 & 20 \\
Feelings of Passivity Direction Relations & 0.878 & 7 \\
Low Personal Achievement & 0.833 & 5 \\
Job Burnout & 0.774 & 8 \\
\hline Satisfaction & 0.780 & 14 \\
\hline
\end{tabular}

14.1 Description the characteristics of the sample

Table 3. Distributing the sample phrases according to demographic variables

\begin{tabular}{|c|c|c|c|c|c|c|c|}
\hline \multirow{2}{*}{ Variable } & \multirow{2}{*}{ Categories } & \multicolumn{2}{|c|}{$\begin{array}{c}\text { Public } \\
\text { Universities }\end{array}$} & \multicolumn{2}{|c|}{$\begin{array}{c}\text { Private } \\
\text { Universities }\end{array}$} & \multicolumn{2}{|c|}{ Total } \\
\hline & & No. & $\%$ & No. & $\%$ & No. & $\%$ \\
\hline \multirow{2}{*}{ Sex } & Male & 49 & 49.0 & 61 & 61.0 & 110 & 55.0 \\
\hline & Female & 51 & 51.0 & 39 & 30.0 & 90 & 45.0 \\
\hline \multirow{2}{*}{$\begin{array}{l}\text { Marital } \\
\text { Status }\end{array}$} & Single & 34 & 34.0 & 48 & 48.0 & 82 & 41.0 \\
\hline & Married & 66 & 66.0 & 52 & 52.0 & 118 & 59.0 \\
\hline \multirow{4}{*}{ Age } & Less than 25 years & 18 & 18.0 & 9 & 9.0 & 27 & 13.5 \\
\hline & $\begin{array}{l}\text { From } 25 \text { to less than } \\
\qquad 35\end{array}$ & 50 & 50.0 & 38 & 38.0 & 88 & 44.0 \\
\hline & $\begin{array}{l}\text { From } 35 \text { to less than } \\
\qquad 45\end{array}$ & 19 & 19.0 & 39 & 39.0 & 58 & 29.0 \\
\hline & 45 years and over & 13 & 13.0 & 14 & 14.0 & 27 & 13.5 \\
\hline \multirow{4}{*}{ Experience } & Less than two years & 21 & 21.0 & 3 & 3.0 & 24 & 12.0 \\
\hline & From 2 to less than 5 & 10 & 10.0 & 24 & 24.0 & 34 & 17.0 \\
\hline & From 5 to less than 10 & 38 & 38.0 & 42 & 42.0 & 80 & 40.0 \\
\hline & 10 years and over & 31 & 31.0 & 31 & 31.0 & 62 & 31.0 \\
\hline \multirow{4}{*}{ Qualification } & Less than a university & 18 & 18.0 & 13 & 13.0 & 31 & 15.5 \\
\hline & Bachelor & 69 & 69.0 & 78 & 78.0 & 147 & 73.5 \\
\hline & Postgraduate & 13 & 13.0 & 9 & 9.0 & 22 & 11.0 \\
\hline & Total & 100 & 100.0 & 100 & 100.0 & 200 & 100.0 \\
\hline
\end{tabular}

Table 3 shows the following:

Sex: it is found that the administrative staffs of the male and female ratios are convergent in public universities, while in private universities there is a higher ratio of males than females.

Marital status: showed the ratio of married individuals were equivalent to two-thirds of the ratio of singles in public universities, while the ratios of both groups were convergent in private universities. 
Age: showed that individuals who were aged 25 years to less than 35 years were the most common in the public universities, amounting to half of the sample size in this category, the rest of categories are fairly close to each other, while in private universities it was shown that people of this age that were located in the second and third categories constituted three-quarters of the sample size.

Experience: it appeared that most of the categories in terms of experience in public universities were of the third category, followed by the fourth category which was less than the first and second, while was the ranking in private universities was noted to be the third category then the fourth, then the second, then first.

Qualifications: found in public universities and private universities that the bachelor's qualification campaign made up the largest proportion, followed by less than a university qualification and finally qualification postgraduate.

\subsection{Descriptive Statistics for Research Variables}

Table 4. Mean and standard deviations for the search variables

\begin{tabular}{lcccc}
\hline \multirow{2}{*}{ Variables } & \multicolumn{2}{c}{ Public Universities } & \multicolumn{2}{c}{ Private Universities } \\
\cline { 2 - 5 } & Mean & St.d & Mean & St.d \\
\hline Emotional and Physical Exhaustion & 3.45 & 0.927 & 3.37 & 0.960 \\
$\begin{array}{l}\text { Feelings of Passivity Direction } \\
\text { Relations }\end{array}$ & 3.30 & 0.862 & 3.13 & 1.06 \\
Low Personal Achievement & 3.46 & 0.693 & 3.40 & 0.685 \\
Job Burnout & 3.42 & 0.700 & 3.32 & 0.777 \\
\hline \multicolumn{1}{c}{ Satisfaction } & 3.17 & 0.743 & 3.31 & 0.643 \\
\hline
\end{tabular}

Table 4 shows the following:

1. That level of job burnout of administrative staff was average at each of the public universities and private universities, however, these workers were more vulnerable to burnout in the public universities than the private universities, where the average of job burnout was 3.42 as opposed to 3.37 .

2. That there were more dimensions of job burnout amongst workers in the public universities such as dimension of low personal achievement with a mean 3.46 and standard deviation 0.693 and then dimension of emotional and physical exhaustion with a mean 3.45 and standard deviation 0.927 and finally dimension of the feeling of negativity in relationships with a mean 3.3 and a standard deviation 0.862 .

3. That there were more dimensions of job burnout present amongst workers in private universities such as dimension of low personal achievement with a mean 3.4 and standard deviation 0.685 and then dimension of emotional and physical exhaustion with a mean 3.37 and standard deviation 0.96 and finally dimension of feelings of negativity in relationships with a mean 3.13 and standard deviation 1.06 . 
4. That the level of satisfaction for workers in public universities and private universities in general was average where it reached mean of satisfaction in public universities 3.17 and a standard deviation of 0.743 , while there was an observed mean of satisfaction in private universities 3.31 and a standard deviation of 0.643 this shows that workers in the private universities have more satisfaction than those working in the public universities.

\subsection{Hypotheses Test}

First Hypothesis: There are no significant differences of moral indications between public universities and private universities in terms of the level of job burnout.

Table 5. Independent Samples T-Test for job burnout

\begin{tabular}{ccccccc}
\hline Variable & $\begin{array}{c}\text { Mean } \\
\text { Public } \\
\text { Universiti } \\
\text { es }\end{array}$ & $\begin{array}{c}\text { Mean } \\
\text { Private } \\
\text { Universiti } \\
\text { es }\end{array}$ & $\begin{array}{c}\text { Mean } \\
\text { Differenc } \\
\text { e }\end{array}$ & T & Sig & $\begin{array}{c}\text { Statistical } \\
\text { Significance }\end{array}$ \\
\hline $\begin{array}{c}\text { Job } \\
\text { Burnout }\end{array}$ & 3.42 & 3.32 & .10 & .725 & .471 & Non Significant \\
\hline
\end{tabular}

Table 5 shows the following:

That the mean differences between job burnout in public universities and job burnout in private universities was 0.10 meaning that workers in public universities suffered a greater amount of burnout than workers in private universities and therefore there are differences between them and in order to know whether these differences were significant or not, the t-test was used for samples independent.

The value 't' was 0.725 with the level of significance of 0.471 which was greater than 0.05 and thus there were no significant differences between public universities and private universities regarding job burnout.

Accordingly the first hypothesis is accepted with regard to the non-existence of significant differences between public universities and private universities from where job burnout.

Second Hypothesis: There are no significant differences of moral indications between public universities and private universities in terms of the level of employees satisfaction.

Table 6. Independent Samples T-Test for Satisfaction

\begin{tabular}{ccccccc}
\hline Variable & $\begin{array}{c}\text { Mean } \\
\text { Public } \\
\text { Universiti } \\
\text { es }\end{array}$ & $\begin{array}{c}\text { Mean } \\
\text { Private } \\
\text { Universiti } \\
\text { es }\end{array}$ & $\begin{array}{c}\text { Mean } \\
\text { Differenc } \\
\text { e }\end{array}$ & T & Sig & $\begin{array}{c}\text { Statistical } \\
\text { Significance }\end{array}$ \\
\hline $\begin{array}{c}\text { Satisfacti } \\
\text { on }\end{array}$ & 3.17 & 3.31 & -.14 & -1.10 & .273 & Non Significant \\
\hline
\end{tabular}

Table 6 shows the following: 


\section{Nl Macrothink}

Journal of Management Research

ISSN 1941-899X

2015, Vol. 7, No. 4

That the mean difference between satisfaction of workers in public universities and satisfaction of workers in private universities was -0.14 which meant that workers in private universities obtained greater satisfaction than workers in public universities and therefore there were differences between them and to know whether these differences were significant or not, the t-test was used for samples independent.

The value' $t$ ' was -1.1 with the level of significance 0.273 which was greater than 0.05 and thus there were no significant differences between public universities and private universities with regards to satisfaction.

Accordingly the second hypothesis is accepted with regard to the non-existence of significant differences between public universities and private universities with regards to satisfaction.

Third Hypothesis: Job burnout levels among employees in private universities and in public universities do not differ based on their demographic properties (gender, marital status, age, experience and qualifications).

In Sector of Public Universities:

Table 7. Mann-Whitny test to job burnout according to sex \& marital status in public universities

\begin{tabular}{cccccc}
\hline Variable & Categories & Mean Rank & Z & Sig & $\begin{array}{c}\text { Statistical } \\
\text { Significance }\end{array}$ \\
\hline Sex & Male & 47.76 & -.273 & .785 & $\begin{array}{c}\text { Non } \\
\text { Significant }\end{array}$ \\
\hline Female & 46.23 & 46.82 & -.045 & .964 & $\begin{array}{c}\text { Non } \\
\text { Significant }\end{array}$ \\
\hline
\end{tabular}

Table 7 shows the following:

Sex: it is noted that the mean ranks for both males and females are very convergent and that the value of Sig (.785) which is greater than the significance level (0.05) and thus non-existence significant differences between males and females from where the degree of job burnout in public universities.

Marital Status: it is noted that the mean ranks for each category single and category married very convergent and that the value of Sig (.964) which is greater than the significance level $(0.05)$ and thus non-existence significant differences between the two categories (single and married) from where the degree of job burnout in public universities. 
Table 8. Levine's test to job burnout according to (age, ex., qual.) in public universities

\begin{tabular}{ccccc}
\hline Variable & Levine's & Sig & $\begin{array}{c}\text { Statistical } \\
\text { Significance }\end{array}$ & $\begin{array}{c}\text { Appropriate } \\
\text { Test }\end{array}$ \\
\hline Age & 0.105 & 0.957 & $\begin{array}{c}\text { Non } \\
\text { Significant } \\
\text { Non } \\
\text { Significant }\end{array}$ & $\begin{array}{c}\text { One- Way } \\
\text { ANOVA } \\
\text { One- Way } \\
\text { ANOVA }\end{array}$ \\
\hline Qualification & 1.08 & 0.743 & $\begin{array}{c}\text { Non } \\
\text { Significant }\end{array}$ & $\begin{array}{c}\text { One- Way } \\
\text { ANOVA }\end{array}$ \\
\hline
\end{tabular}

Table 8 shows the following: that all the variables is not statistically significant which means achieve the condition equal to the variance between the groups and thus use One- Way ANOVA.

Table 9. One- Way ANOVA test to job burnout according to (age, ex., qual.) in public universities

\begin{tabular}{|c|c|c|c|c|c|}
\hline Variable & Categories & Mean & $\mathrm{F}$ & Sig. & $\begin{array}{c}\text { Statistical } \\
\text { Significance }\end{array}$ \\
\hline \multirow{4}{*}{ Age } & Less than 25 years & 3.20 & \multirow{4}{*}{.765} & \multirow{4}{*}{.516} & \multirow{4}{*}{$\begin{array}{c}\text { Non } \\
\text { Significant }\end{array}$} \\
\hline & From 25 to less than 35 & 3.48 & & & \\
\hline & From 35 to less than 45 & 3.39 & & & \\
\hline & 45 years and over & 3.53 & & & \\
\hline \multirow{4}{*}{ Experience } & Less than two years & 3.15 & \multirow{4}{*}{2.286} & \multirow{4}{*}{.084} & \multirow{4}{*}{$\begin{array}{c}\text { Non } \\
\text { Significant }\end{array}$} \\
\hline & From 2 to less than 5 & 3.31 & & & \\
\hline & From 5 to less than 10 & 3.38 & & & \\
\hline & 10 years and over & 3.66 & & & \\
\hline \multirow{3}{*}{ Qualification } & Less than a university & 3.55 & \multirow{3}{*}{.950} & \multirow{3}{*}{.391} & \multirow{3}{*}{$\begin{array}{c}\text { Non } \\
\text { Significant }\end{array}$} \\
\hline & Bachelor & 3.42 & & & \\
\hline & Postgraduate & 3.19 & & & \\
\hline
\end{tabular}

Table 9 shows the following:

Age: it is noted that all age groups suffer medium degree of job burnout in public universities with simple differences between them, and the value of sig. 0.516 which is greater than the significance level of 0.05 , and thus indicates the lack of significant differences between age groups of degree of job burnout in public universities.

Experience: it is noted that all employees of the various years of experience suffer medium degree of job burnout in public universities with simple differences between them, and the value of sig. 0.084 which is greater than the significance level of 0.05 and thus the lack of significant differences between categories experience of degree of job burnout in public universities. 
Qualification: it is noted that all categories of qualification suffered medium degree of job burnout in public universities with simple differences between them, and the value of sig. 0.391 which is greater than the significance level of 0.05 and thus the lack of significant differences between the qualification categories of degree job burnout in public universities.

Based on previous results the third hypothesis was accepted that in public universities with regard to non-different degree of job burnout amongst workers in different variables (sex, marital status, age, experience, qualification).

In Sector of private Universities:

Table 10. Mann-Whitny test to job burnout according to sex \& marital status in private universities

\begin{tabular}{cccccc}
\hline Variable & Categories & Mean Rank & Z & Sig & $\begin{array}{c}\text { Statistical } \\
\text { Significance }\end{array}$ \\
\hline Sex & Male & 23.44 & -0.393 & 0.694 & $\begin{array}{c}\text { Non } \\
\text { Significant }\end{array}$ \\
\hline Female & 25.09 & 23.40 & -0.045 & 0.789 & $\begin{array}{c}\text { Non } \\
\text { Significant }\end{array}$ \\
\hline
\end{tabular}

Table 10 shows the following:

Sex: it is noted that the mean ranks for both males and females are convergent and that the value of sig. 0.694 which is greater than the significance level of 0.05 and thus non-existent significant differences between males and females from where the degree of job burnout in private universities.

Marital Status: it is noted that the mean ranks for each category single and category married very convergent and that the value of sig (.789) which is greater than the significance level (0.05) and thus non existence significant differences between the two categories (single and married) from where the degree of job burnout in private universities.

Table 11. Levine's test to job burnout according to (age, ex., qual.) in private universities

\begin{tabular}{ccccc}
\hline Variable & Levine's & Sig & $\begin{array}{c}\text { Statistical } \\
\text { Significance }\end{array}$ & $\begin{array}{c}\text { Appropriate } \\
\text { Test }\end{array}$ \\
\hline Age & 2.11 & 0.101 & $\begin{array}{c}\text { Non } \\
\text { Significant }\end{array}$ & $\begin{array}{c}\text { One- Way } \\
\text { ANOVA } \\
\text { Experience }\end{array}$ \\
\hline Qualification & 7.58 & 0.003 & Significant & K - W \\
\hline
\end{tabular}

Table 11 shows the following: the age variable is not statistically significant which means the condition equal achieved the variance between the groups and thus used One- Way ANOVA. The variables (experience $\&$ qualification) are statistically significant and therefore did not 
achieve the condition equal to the variance between the groups and thus use the Kruskal-Wallis.

Table 12. One- Way ANOVA test to job burnout according to age in private universities

\begin{tabular}{|c|c|c|c|c|c|}
\hline $\begin{array}{l}\text { Variabl } \\
\text { e }\end{array}$ & Categories & Mean & $\mathrm{F}$ & Sig. & $\begin{array}{c}\text { Statistical } \\
\text { Significance }\end{array}$ \\
\hline \multirow{4}{*}{ Age } & Less than 25 years & 2.92 & \multirow{4}{*}{.765} & \multirow{4}{*}{.618} & \multirow{4}{*}{$\begin{array}{l}\text { Non } \\
\text { Significant }\end{array}$} \\
\hline & From 25 to less than & 3.32 & & & \\
\hline & $\begin{array}{r}\text { From } 35 \text { to less than } \\
45\end{array}$ & 3.45 & & & \\
\hline & 45 years and over & 3.29 & & & \\
\hline
\end{tabular}

Table 12 shows the following: that the age groups suffer medium degree of job burnout with some slight differences among these groups except in the first category, and the value of sig. 0.618 which is greater than the significance level of 0.05 and thus showed a lack of significant differences between age groups of job burnout in private universities.

Table 13. K-W. test to job burnout according to (ex. \& qual.) in private universities

\begin{tabular}{cccccc}
\hline Variable & Categories & Mean Rank & 2Chi & Sig & $\begin{array}{c}\text { Statistical } \\
\text { Significance }\end{array}$ \\
\hline & Less than two years & 10.75 & & & \\
Experience & From 2 to less than 5 & 22.27 & 2.37 & .498 & $\begin{array}{c}\text { Non } \\
\text { Significant }\end{array}$ \\
& From 5 to less than 10 & 25.15 & & & \\
\hline Qualificatio & Less than a university & 13.19 & & & \\
$\mathrm{n}$ & Bachelor & 26.50 & 6.147 & .046 & Significant \\
\hline
\end{tabular}

Table 13 shows the following:

Experience: it is noted that the mean ranks for all categories of years of experience are close to each other except for the first category and everyone suffers medium degree of job burnout in private universities, and the value of sig. 0.498 which is greater than the significance level of 0.05 and thus the lack of significant differences between categories of expertise of the degree of job burnout in private universities.

Qualification: it is noted that all categories of qualification suffer medium degree of job burnout in private universities, and the value of sig. 0.046 which is less than the significance level of 0.05 , and thus there are significant differences between the categories of qualification of the degree of job burnout in private universities.

Based on previous results the third hypothesis is accepted, partly in private universities with regard to non-different degree of job burnout amongst workers in different variables (sex, 
marital status, age, experience) and its refusal with regard to the different degree of job burnout amongst workers in different variable qualification.

Fourth hypothesis: There is no significant difference between the level of employees satisfaction in public universities and private universities and the level of natural employee satisfaction.

This hypothesis will be tested once in public universities' sector and again in private universities' sector using one sample t-test, to make sure the significant of differences between the overall mean satisfaction of the employees and the imposed mean of 4.0 which is equivalent to a good degree of the scale.

In Sector of Public Universities:

Table 14. One Sample T-Test for the satisfaction of the employees in public universities

\begin{tabular}{cccccccc}
\hline Variable & $\begin{array}{c}\text { Imposed } \\
\text { Mean }\end{array}$ & Mean & $\begin{array}{c}\text { Mean } \\
\text { Difference }\end{array}$ & St.d & T & Sig. & $\begin{array}{c}\text { Statistical } \\
\text { Significanc } \\
\mathrm{e}\end{array}$ \\
\hline $\begin{array}{c}\text { Satisfactio } \\
\mathrm{n}\end{array}$ & 4.00 & 3.17 & -.83 & .743 & -10.71 & .000 & $\begin{array}{c}\text { Non } \\
\text { Significant }\end{array}$ \\
\hline
\end{tabular}

Table 14 shows the following:

The mean for the satisfaction of the employees was 3.17, which is less than the imposed mean of 4.0 and therefore the level of satisfaction of the employees was medium in public universities.

The value of' $t^{\prime}$ was -10.71 at the significant level of 0.00 and is less than 0.05 , and this indicates the presence of significant differences between the mean satisfaction of the employees in the public universities and the mean of natural satisfaction for employees.

In Sector of private Universities:

Table 15. One Sample T-Test for the satisfaction of the employees in private universities

\begin{tabular}{cccccccc}
\hline Variable & $\begin{array}{c}\text { Imposed } \\
\text { Mean }\end{array}$ & Mean & $\begin{array}{c}\text { Mean } \\
\text { Difference }\end{array}$ & St.d & T & Sig. & $\begin{array}{c}\text { Statistical } \\
\text { Significanc } \\
\text { e }\end{array}$ \\
\hline $\begin{array}{c}\text { Satisfactio } \\
\mathrm{n}\end{array}$ & 4.00 & 3.31 & -.69 & .643 & -7.30 & .000 & $\begin{array}{c}\text { Non } \\
\text { Significant }\end{array}$ \\
\hline
\end{tabular}

Table 15 shows the following:

The mean for the satisfaction of the employees was 3.31, which is less than the imposed mean of 4.0 and therefore the level of satisfaction of the employees was medium in private universities. 
The value of ' $t$ ' was -7.30 at the significant level of 0.00 and is less than 0.05 , and this indicates the presence of significant differences between the mean satisfaction of the employees in the private universities and the mean of natural satisfaction for employees.

Based on previous results the fourth hypothesis is rejected and accept the alternative hypothesis which stated that the existence of significant difference between the mean level of satisfaction of employees in public universities and private universities and between the mean of natural satisfaction for employees.

Fifth Hypothesis: Job burnout dimensions (emotional and physical exhaustion, negative attitude towards relationships and low personal achievement) do not morally affect on employees satisfaction in public universities and private universities.

In Sector of Public Universities:

Table 16. Model Summary in Public Universities

\begin{tabular}{cccccc}
\hline F & Sig & R & R2 & Adjusted R2 & S. E. \\
\hline 2.11 & .104 & .258 & .066 & .035 & .730 \\
\hline
\end{tabular}

Table 17. Coefficients in Public Universities

\begin{tabular}{cccccc}
\hline Variables & $\mathrm{B}$ & Std. Error & Beta & $\mathrm{T}$ & Sig. \\
\hline $\begin{array}{c}\text { Constant } \\
\text { Emotional and } \\
\text { Physical } \\
\text { Exhaustion }\end{array}$ & 3.005 & .402 & & 7.470 & .000 \\
$\begin{array}{c}\text { Feelings of } \\
\text { Passivity Direction } \\
\text { Relations }\end{array}$ & -.334 & .135 & -.387 & -2.470 & .115 \\
\hline $\begin{array}{c}\text { Low Personal } \\
\text { Achievement }\end{array}$ & .224 & .145 & .209 & 1.544 & .126 \\
\hline
\end{tabular}

From tables (16) \& (17) noted following:

The value of $\mathrm{F}$ was 2.11 with the level of significant of 0.104 , is non-statistically significant because it is greater than 0.05 , and therefore does not verify the used model in test of the influential relationship between dimensions of job burnout and satisfaction of employees in public universities, which means that this model with its independent variables is not able to be used to predict the value of the dependent variable.

Does not affect any dimension from dimensions of the job burnout significantly in satisfaction of the employees.

The correlation coefficient $\mathrm{R}$ between the independent variable and the dependent variable is 0.258 , a weak correlation between the two variables, the coefficient of determination R2 is 
0.066 , which means that the independent variable does not explain only a percentage is simple in the dependent variable.

Thus: accept fifth hypothesis in public universities, which means that the dimensions of job burnout does not affect (emotional and physical exhaustion, feelings of passivity direction relations, low personal achievement) significantly in satisfaction of the employees.

In Sector of private Universities:

Table 18. Model Summary in private Universities

\begin{tabular}{cccccc}
\hline F & Sig & R & R2 & Adjusted R2 & S.E. \\
\hline 8.92 & .000 & .620 & .384 & .341 & .522 \\
\hline
\end{tabular}

Table (19): Coefficients in private Universities

\begin{tabular}{|c|c|c|c|c|c|}
\hline Variables & B & Std. Error & Beta & $\mathrm{T}$ & Sig. \\
\hline Constant & 1.423 & .393 & & 3.621 & .001 \\
\hline $\begin{array}{c}\text { Emotional and } \\
\text { Physical } \\
\text { Exhaustion }\end{array}$ & -.184 & .181 & -.275 & -1.020 & .313 \\
\hline $\begin{array}{c}\text { Feelings of } \\
\text { Passivity Direction } \\
\text { Relations }\end{array}$ & .225 & .151 & .372 & 1.489 & .144 \\
\hline $\begin{array}{l}\text { Low Personal } \\
\text { Achievement }\end{array}$ & .532 & .142 & .567 & 3.743 & .001 \\
\hline
\end{tabular}

From tables (18) \& (19) noted following:

The value of F was 8.92 with the level of significant of 0.00 , is statistically significant because it is less than 0.05 , and therefore the validity of the model used in test of the influential relationship between dimensions of job burnout and satisfaction of employees in the private universities, which means that this model with its independent variables is able to be used to predict the value of the dependent variable.

One dimension affect only of the dimensions of a job burnout (low personal achievement) significantly in satisfaction of the employees.

The correlation coefficient $\mathrm{R}$ between the independent variable and the dependent variable is 0.62 , which is correlation medium of force between the two variables, and the coefficient of determination R2 is 0.384 , this means that the independent variable explains amount of $38.4 \%$ of the changes in the dependent variable, it is an acceptable rate.

Thus: accept the fifth hypothesis partly in private universities with regard to the non- effect of job burnout dimensions (emotional and physical exhaustion, feelings of passivity direction 
relations) is significant in satisfaction of the employees, and partly rejected with regard to the existence of the effect of the dimension of job burnout (low personal achievement) significantly in satisfaction of the employees.

\section{Discussion and Conclusions}

The level of job burnout amongst administrators in public and private universities sector has exceeded the medium level. It means that these employees are suffering from psychological and physical tension and have a negative attitude and low personal achievement, which can be attributed to their administrative work in the educational sector. Their work is governed by laws and regulations that make employee feels bored and performs a typical and dull job, free of any innovation, creativity and renovation. The level of job burnout in public universities is higher that its level in private universities. That is attributed to continued work pressure, intense work hours and increased number of students who visit their departments; particularly during the registration and examination period as the number of students is larger, compared to that in private universities, in addition to the absence of appreciation awarded to these employees.

Low personal performance dimension has ranked the first as the most persistent job burnout dimension in public and private universities. It is attributed to the lack of consistency between the work nature and the nature of employee engaged in performing such work, incompetency of some employees, low enthusiasm and weak productivity. Physical and emotional exhaustion dimension ranked the second as it is attributed to increased stress, overtasks, depression, long working hours, lack of mental and practical concentration, sleep disorders, insomnia, and headaches. The third rank is allocated for the dimension of negative attitude towards relationships. It is due to the problems arising from sarcasm, aggression in the work place, disputes, tension, bad manners when dealing with colleagues, lack of confidence and sensitivity in dealing with others.

In general, employee satisfaction in public universities and private universities, sample of the research, achieves the minimum of the medium level. Employee satisfaction in public universities is less than their satisfaction in private universities. The reason might be attributed to differences in the salaries and wages, absence of satisfaction for the material returns and additional benefits that are not compatible with their qualifications and efforts, lack of satisfaction from the promotion system, advancement of positions and relationships with colleagues; as well as low supervisory quality and non-participation in making decisions related to their jobs.

There are no significant differences between males and females in terms of job burnout in public and private universities, as there are not any differences between men and women in terms of their academic level, equality in job burdens and equal job opportunities.

There are no significant differences between single employees and married employees in terms of job burnout in public and private universities. The reason behind this is the fact that both the single and the married employees share the same family burdens and seek to support themselves and their families. 
There are no significant differences in job burnout among employees of private and public universities in terms of their age group. The reason is that all employees, of all ages, understand their tasks, job roles and their job requirements, as well as all liabilities with regard to increased work load and the need to prove themselves.

There are no significant differences in job burnout cases among employees of public and private universities in terms of experience. If the years of experience increase without any personal achievement for the employee or any ability to take significant resolutions related to their work or any promotion, they will suffer from job burnout. Likewise, young employees have high expectations and ambitions at the beginning of their work life. However, they are mostly shocked by the reality of the work in a way that is causing a feeling of dissatisfaction on their work achievements.

There are no significant differences in job burnout among employees of public universities in terms of academic qualifications. They are similar in nature of administrative work and at various administrative levels in public universities. Therefore, the level of suffering from job burnout is approximate for the different age groups.

There are significant differences in job burnout cases among employees of private universities in terms of academic qualifications. Holders of university degrees are the majority of personnel suffering from job burnout. This can be attributed to the fact that most employees of private universities who hold administrative positions are holders of bachelor degrees. As a result, they are responsible for the majority of the work load. In addition, their work is characterised as typical, boring and repetitive with a requirement of direct contact with students and visitors; thus, their psychology and performance is affected.

There is a significant difference between the average level of employee satisfaction in public universities and private universities and the average level of natural satisfaction among employees. It is stipulated that the level of job satisfaction among employees in both the private and the public sectors is less than the natural satisfaction level. This is attributed to low salaries, wages and awards, the prevailing supervisory pattern, the work content and lack of promotion opportunities.

No dimension of job burnout (emotional and physical exhaustion, negative attitude towards relationships and low personal achievement) morally affects on employees satisfaction in public universities. However, only one dimension (low personal achievement) affects employee's satisfaction in private universities. It is attributed to the fact that if the employee has failed in personal achievements, they have a feeling of low efficiency at work, lost the feeling of compliance in work relationships and fail to achieve their ambitions and expectations, their sufferings and depression would increase, generating a feeling of dissatisfaction with regard to their achievements and relationships with supervisors and leaders; thus, the performance of the university as a whole would be adversely affected.

\section{Recommendations}

First: Recommendations for the public and private universities of the research sample 
Set work priorities at private and public universities; work on the basis of pre-identified plans according to a specific time schedule; allocate a time for rest and do not constantly engage in work tasks; never neglect the personal life but seek to have a balanced life.

Set a reasonable ceiling for administrative work burdens in the educational sector; particularly in public universities. Such burdens should correspond with the person's abilities; considering justice and quality in distributing job burdens among individuals; clearly identify the roles and responsibilities and adopt a policy of job rotation. The employee should not work in the same position for more than 4 years.

Utilise the abilities and competencies of the university employees in the right and correct manner and develop these capacities and skills by periodically and regularly attending conferences, forums and training courses in a way satisfying employees' requirements.

Hold awareness courses for employees on job burnout phenomena, educating them on how to deal with and overcome challenges; allowing them a sufficient scope of independency in making their own decisions related to work; encouraging them to cooperate and become fully prepared to provide psychological support at the work place.

Take care of employees, particularly newly appointed employees; provide advice, consultation and appropriate protective procedures and help them become involved in the work process; enable them to achieve a balance between their ambitions and their work reality.

Study the psychological structure of the employee; analyse their behaviour inside and outside the work environment; avoid satisfying supervisors by hurting oneself and feeling dissatisfied.

Create a fair and fixed system for the salaries and motivations, both moral and material, in a way that corresponds with the effort made by the employee to satisfy their basic needs and those of their family.

Highlight the importance of cooperation between public universities and private universities to exchange experience and knowledge and peruse the latest developments and updates in the educational sector.

Both public and private universities should give a special attention to the entertainment of their personnel in order to break the ice, rigidness and routine in performing their work and creating entertaining programs that renovate their employee energies, such as trips, celebrating events and holidays to foster social relationships, support, networking and assistance among colleagues.

Activate and reinforce human relationships amongst employees and visitors; connect them with the social and human reality that affects their work; focus on serving visitors from a human aspect for its significant effects on the psychological aspects of the employees and their human feelings and its benefit in promoting their job satisfaction levels and attachment to work.

Take care of employee satisfaction at private or public universities; increase their job satisfaction levels; particularly the feeling of satisfaction for their material revenue, extra 
benefits and satisfaction for the promotion policy as the wages and promotion opportunities have a significant importance for employees as it represents a motivation for work and creativity and promotes self-esteem.

Second: Recommendations for Future Research

Study the relationship between job burnout and organisational loyalty.

Study the relationship between job burnout and creativity.

Study the effect of job burnout on the effectiveness of performance.

\section{References}

Alexander, D., \& Klein, S. (2001). Ambulance Personnel and Critical Incidents - Impact of Accident and Emergency Work on Mental Health and Emotional Well-Being, British Journal of Psychiatry, 178, 76-81. http://dx.doi.org/10.1192/bjp.178.1.76

Ben-Zur, H., \& Yagil, D. (2005). The relationship between Empowerment, Aggressive Behaviours of Customers, Coping and Burnout. European Journal of Work and Organizational Psychology, 14(1), 81-100. http://dx.doi.org/10.1080/13594320444000281

Brotheridge, C., \& Grandey, A. (2002). Emotional Labour and Burnout: Comparing Two Perspectives of "People Work". Journal of Vocational Behaviour, 60(1), 17-39. http://dx.doi.org/10.1006/jvbe.2001.1815

Capri, Burhan, O., Osman M., Ozkurt, B., \& Karakus, F. (2012). General Self-Efficacy beliefs, Life Satisfaction and Burnout of University Students, Procedia Social and Behavioral Sciences, 47(1), 968-973. http://dx.doi.org/10.1016/j.sbspro.2012.06.765

Chemiss, C. (1980). Professional Burnout in Human Service Organisations, NewYork: Praeger.

Cordes, C., \& Dougherty, T. (1993). A Review and an Integration of Research on Job Burnout, Academy of Management Review, 18(4), 621-656.

Deery, S., Iverson, R., \& Walsh, J. (2002). Work Relationships in Telephone Call Centres: Understanding Emotional Exhaustion and Employee Withdrawal, Journal of Management Studies, 39(4), 471-496. http://dx.doi.org/10.1111/1467-6486.00300

Demerouti, E., Bakker, A., Nachreiner, F. \& Schaufeli, W. (2007). the Job Demands Resources Model of Burnout, Journal of Applied Psychology, 86, 499-512. http://dx.doi.org/10.1037/0021-9010.86.3.499

Dollard, M., Winefield, H., Winefield, A., \& de Jonge, J. (2000). Psychosocial job strain and productivity in human service workers: a test of the demand-control-support model, Journal of Occupational and Organisational Psychology, 73(4), 501-510. http://dx.doi.org/10.1348/096317900167182

Dormann, C., \& Zapf, D. (2004). Customer-Related Social Stressors and Burnout. Journal of Occupational Health Psychology, 9(1), 61-82. http://dx.doi.org/10.1037/1076-8998.9.1.61 
Farber, B. (1991). Crisis in Education: Stress and Burnout: Assumptions, Myths and Issues, San Francisco, CA: Jossey Bass Publishers.

Friedman, I. (1993). Burnout in Teachers: the Concept and its Unique Core Meaning, $\begin{array}{llll}\text { Educational and Psychological Measurement, } & \text { 53(4), }\end{array}$ http://dx.doi.org/10.1177/0013164493053004016

Fujiwara, K., Tsukishima, E., Tsutsumi, A., Kawakami, N., \& Kishi, R. (2003). Interpersonal Conflict, Social Support, and Burnout Among Home Care Workers in Japan, Journal of Occupational Health, 45(5), 313-320. http://dx.doi.org/10.1539/joh.45.313

Giebels, E., \& Janssen, O. (2005). Conflict Stress and Reduced Well-Being at Work: the Buffering Effect of Third Party Help, European Journal of Work and Organisational Psychology, 14(2), 137-156. http://dx.doi.org/10.1080/13594320444000236

Hancock, L. (1995). Working Your Nerves: the Toughest Jobs, Newsweek, 7 March.

Holman, D., Chissick, C., \& Totterdell, P. (2002). the Effects of Performance Monitoring on Emotional Labour and Well-Being in Call Centres, Motivation and Emotion, 26(1), 57-81. http://dx.doi.org/10.1023/A:1015194108376

Hunsaker S., Chen Hsiu-C., Maughan D., and Heaston S. (2015). Factors That Influence the Development of Compassion Fatigue Burnout, and Compassion Satisfaction in Emergency Department Nurses, Journal of Nursing Scholarship, 47(2), pp.186-194. http://dx.doi.org/10.1111/jnu.12122

Jasperse M., Herst, P., And Dungey G. (2014). Evaluating stress, burnout and job satisfaction in New Zealand radiation oncology departments, European Journal of Cancer Care, 23, 82-88. http://dx.doi.org/10.1111/ecc. 12098

Kaden, R. (1999). Therapist Burnout: the Contributions of Role Stress, Patient Behaviour Stress, and Therapeutic Personality, Unpublished Doctoral Dissertation, Seton Hall University, New Jersey.

Khamisa N., Oldenburg B., Peltzer K., and Ilic D. (2015). Work Related Stress, Burnout, Job Satisfaction and General Health of Nurses. International Journal of Environmental Research and Public Health, 12(1), 652-66. http://dx.doi.org/10.3390/ijerph120100652

Koeske, G. \& Thomas, K. (1995). The Impact of Over-Involvement on Burnout and Job Satisfaction, American Journal of Orthopsychiatry, 65(2), 282. http://dx.doi.org/10.1037/h0079622

Leiter, M., \& Maslach, C. (2001). Burnout and Health. Handbook of health psychology, London: Lawrence Erlbaum.

Leung J., Rioseco P., \& Munro P. (2015). Stress, Satisfaction and Burnout Amongst Australian and New Zealand Radiation Oncologists, Journal of Medical Imaging and Radiation Oncology, 59(1), 115-24. http://dx.doi.org/10.1111/1754-9485.12217 
Lewig, K., \& Dollard, M. (2003). Emotional Dissonance, Emotional Exhaustion and Job Satisfaction in Call Centre Workers. European Journal of Work and Organizational Psychology, 12(4), 366-393. http://dx.doi.org/10.1080/13594320344000200

Linthicum, G. (1994). An Analysis of the Extent to Which School District Superintendents Experience Burnout, Edd Dissertation, University of Montana, Dissertation Abstracts International.

Maslach, C, Jackson, S. (1993). Maslach Burnout Inventory Manual, Consulting Psychologists Press, Inc., Palo Alto, California, $2^{\text {nd }}$ edition.

Maslach, C, Jackson, S. (1996). Maslach Burnout Inventory Manual,. Consulting Psychologists Press, Inc., Palo Alto, California, $3^{\text {rd }}$ Edition. http://dx.doi.org/10.1146/annurev.psych.52.1.397

Maslach, C. (1982). Understanding Burnout: Definitional Issues in Analysing a Complex Phenomenon, in W. S. Paine (Eds), Job Stress and Burnout, Beverly Hills: Sage Publications, $29-40$.

Maslach, C., \& Leiter, M. (1997). The Truth About Burnout, San Francisco: Jossey-Bass.

Maslach, C., Schaufeli, W., \& Leiter, M. (2001). Job Burnout. Annual Review of Psychology, 52, 397-422.

Omdahl, B., \& O'Donnell, C. (1999). Emotional Contagion, Empathic Concern and Communicative Responsiveness as Variables Affecting Nurses' Stress and Occupational Commitment, Journal of Advanced Nursing, 29(6), 1351-1359. http://dx.doi.org/10.1046/j.1365-2648.1999.01021.x

Ozyurek A., Gumus H. and Dogan S. (2012). Examination of Burnout and Life Satisfaction Levels of Teachers and School Administrators, International Journal of Human Sciences, 9(2), 892-904.

Rafferty, Y., Friend, R., \& Landsbergis, P. (2001). The association between job skill discretion, decision authority and burnout. Work and Stress, 15(1), 73-85. http://dx.doi.org/10.1080/02678370120791

Sangganjanavanich V., \& Balkin R. (2013) Burnout and Job Satisfaction Among Counselor Educators, Journal Of Humanistic Counseling, 52, 67-79. http://dx.doi.org/10.1002/j.2161-1939.2013.00033.x

Scanlan J. \& Still M. (2013). Job Satisfaction, Burnout and Turnover Intention in Occupational Therapists Working in Mental Health. Australian Occupational Therapy Journal, 60, 310-318. http://dx.doi.org/10.1111/1440-1630.12074

Schaufeli, W., \& Enzmann, D. (1998). The Burnout companion to study and practice, Taylor \& Francis: London.

Tamini B. \& Kord B. (2011). Burnout Components as Predictors of Job \& Life Satisfaction of University Employees, The Indian Journal of Industrial Relations, 47(1), 126-137. 
Tanis, T., Le Blanc, P., Schaufeli, W., \& Schreurs, P (2005). Are There Causal Relationships between the Dimensions of the Maslach Burnout Inventory? a Review and Two Longitudinal Tests. Work \& Stress, 19, 238-255. http://dx.doi.org/10.1080/02678370500270453

Wertz, J. (2000). Relation of Occupational Stress, Coping Resources, Personal Strain and Burnout in Psychology Interns. Unpublished Doctoral Dissertation, University of Kentucky, Lexington.

Whitaker, K. (1996). Exploring Causes of Principal Burnout, Journal of Educational Administration, 34(1), 60-77. http://dx.doi.org/10.1108/09578239610107165

Zohar, D. (1997). Predicting burnout with a hassle-based measure of role demands. Journal of Organisational Behaviour, $18(2)$, 101-115. http://dx.doi.org/10.1002/(SICI)1099-1379(199703)18:2<101::AID-JOB788>3.0.CO;2-Y 